\section{THE TEACHING OF TROPICAL MEDICINE *}

BY

W. P. MACARTHUR, M.D., F.R.C.P.I.

DREVET COLONEL R.A.M.C. ; CONSLLTING PHYSICIAN TO THE BRITISH ARMY

I presume that this discussion is confined to the teaching of tropical medicine in the various schools as they exist to-day, and that idealistic schemes impossible of realization lie beyond its scope.

The usual duration of courses of instruction for diplomas in tropical medicine and hygiene is five months. That, I think, is long enough. We know that a high standard of knowledge in so complex a group of subjects cannot be acquired within five months, but neither can it in eight or nine. Whatever may be thought elsewhere, neither the teachers nor the examiners consider that a D.T.M. guarantees a specialist standard in tropical medicine, any more than a D.P.H. in itself endows the holder with a profound knowledge of public health. I should not be willing to give my body to be cut up by anyone on the strength of his having just secured a surgical Fellowship. All that can reasonably be expected of a diploma course is to give the student a good sound foundation on which he can build later as occasion offers. It is common knowledge, of course, that these various qualifications are often taken by persons who are already conversant with the subject before they commence the prescribed studies, and this special class I omit from my survey.

Clinical tropical medicine presents the fewest difficulties to the teacher, for this is merely an extension and elaboration of what the candidates know already. The determination of hepatic dullness is the same whether an enlargement is due to amoebic abscess or to biliary cirrhosis. It is true that a multiplicity of cases of the same tropical ailment may not be forthcoming in this country, but this matters less than might appear at first glance, for personal responsibility for the diagnosis and treatment of a disease is the best teacher. Nothing can take the place of first-hand experience, and we will learn more of, say, small-pox from study of one difficult case for the diagnosis of which we are responsible than from a dozen such demonstrated in the wards of a small-pox hospital.

A defective training in general medicine is a great handicap to those taking up the study of tropical disease, and a sore trial to their teachers. It has long been my belief that the standard of knowledge in general medicine is lower to-day than it was when I qualified. Some time ago I had an experience which confirmed this impression. It fell to my lot to examine a number of recently qualified medical men representing many of the teaching schools. Having a clear recollection of the examination in clinical pathology which I and my fellows had passed in order to qualify, I subjected this group of men to an identical test, and of over a dozen only two came up to the standard which was expected, and obtained, in my time. The lack of knowledge shown by some was deplorable. One man assured me that the diagnostic method of choice in typhoid fever is to demonstrate $B$. typhosus by making a direct microscopical examination of the faeces, and was convinced that no other organism with similar morphological characters could be encountered in such a preparation. Whether this state of affairs is due to additional subjects having been squeezed into the medical curriculum, or to some other cause, it is not within my province to say, but I can say that a considerable number of those commencing a course in tropical medicine literally

* Read in opening a discussion in the Section of Tropical Medicine at the Centenary Meeting of the British Medical Association, London, 1932. do not know how to use a microscope, and ought to be excluded by imposing a simple preliminary test, if monetary and other considerations permitted.

To most of the members of a tropical medicine class, parasitology, in its several branches, is new ground. I do not know if the subject is supposed to be taught in our medical schools, but up to the present such students as I have encountered had no knowledge of it worth mentioning, and the few animal parasites which they had heard of were mostly called by olssolete synonyms-Trichocephalus dispar, Acarus scabiei, Pediculus vestimentorum, and the like. I am no unreasonable purist in these matters, and am unorthodox enough to contend that the rules of nomenclature were made for man, and not man for the rules of nomenclature. Still, it seems a pity to burden the minds of medical students with useless synonyms which should be known only to those given to archaeological delvings.

As I have said already, clinical medicine in a D.T.M. course is largely a continuation of what has gone before, but as regards protozoology, helminthology, and entomology the students are like children learning to read. The eye must be trained to see and recognize characters not familiar before. It is not much good if a child is able to describe the appearance of the letter A, and then. fails to recognize an $\mathrm{A}$ when he is shown one. Nor will he make satisfactory progress in reading if he is blundering and guessing his way through words of several syllables while still uncertain of the identity of the letters which make them up. And so, too, in the teaching of parasitology, the course should be restricted to essentials, for the time allotted is necessarily short, and those undergoing instruction tend to be overwhelmed with masses of information new to them, and so fail to sift out and grasp the points of basic importance. It is absurd to expect a class to know the characters of, say, one of the less common intestinal flagellates when they can still be shaken in their identification of a malaria parasite. I remember one examination candidate who himself introduced a discussion on the ova of some of the rarer helminths of man, on which he discoursed with unction. Then, being given a microscope and a faeces preparation, he carefully selected a bit of vegetable debris and identified it as an egg of, I think, Trichostrongylus colubriformis. That is tropical medicine upside down. And for anyone who cannot be relied on to say whether a given object is an egg or not, even to mention $T$. colubriformis should be an indictable offence.

I believe that the teaching of parasitology should follow the lines of zoological classification, so as to keep a broad outlook, but that detailed instruction should be confined to parasites of outstanding importance, and the class kept to the study of these until the teachers themselves would accept their pupils' identification. This slow and careful progression from step to step gives the learners confidence in themselves, and they are therefore fitted to add to their knowledge later when time and opportunity permit. But to rush them on to, say, haemogregarines when they are still at the stage of possibly mistaking blood platelets or vacuoles for parasites is, to my mind, teaching gone mad. They do not know themselves what they know, and, what is infinitely worse, they do not realize their own limitations, and after a few seconds' scrutiny, with all the confidence of ignorance, will give an identification which might take an expert hours or days to arrive at.

The system I advocate enables the student to identify definitely only a small number of parasites, but then he knows when he encounters something that he has not seen before, and although he cannot say what it is, he has the great advantage of knowing what it is not, and in actual practice can take steps to ascertain its nature. Also it will cause a welcome diminution of faith, the 
faith that removes mountains, the faith that perceives parasites which are not there. This sin, when committed in an examination, should automatically cause disqualification, no matter how the candidate may have acquitted himself in other respects.

But however well arranged the course and ample the material, the main factor in success is the personality of the teacher. A man either can teach or he cannot. $\mathrm{He}$ cannot learn to teach any more than he can learn to write poetry, though practice may improve both arts. He must, of course, be thoroughly conversant with his subject, and possess first-hand knowledge of it, but that is not sufficient. We all know men, justly renowned for their learning, who can be trusted to make any subject, whatever its potential interest, as dull as ditchwater. And we know others who have the power of making any subject interesting: I have heard a lecture on Middle English grammar that held me spellbound. Unfortunately we cannot tell for ourselves whether or not we can lecture well, for there are no standards for comparison. Success depends, I suppose, on the possession of that indefinable power which actors call "getting across" and all that it comprises, on an instinct for narrative values, and with these some degree of enthusiasm, for a lecturer is not likely to be successful if he regards his teaching duties merely as an unpleasant interruption of more congenial tasks. Over a period of several years I examined students of the same type, in the same branch of tropical medicine, in three institutions, and invariably found the same differences-in one to examine the average candidate was a pleasure ; in the second the best candidates knew all that could reasonably be expected of them; while in the third they would nearly all have hanged themselves if given enough rope. Examples of excellent, of competent, and of bad teaching respectively. (In order to circumvent possible attempts at identification I should like to state that I have examined in considerably more than the number of institutions just mentioned.)

I am of opinion that in making appointments to teaching posts in universities and elsewhere, sufficient attention is not paid to what, at any rate professedly, would be the applicant's main duty. I have been a member of a committee nominated to report on the suitability of a candidate for appointment as lecturer. His academic qualifications were considered; his published papers were read and debated at length-and I do not minimize the importance of these matters. But none of my fellow members thought it worth while to inquire whether he could teach.

The main shortcomings to be found in courses in tropical medicine seem to me to be due to: overcrowding of the curriculum; lack of individual attention through unwieldiness of the class, shortage of staff, or both; an insufficient allotment of time for the hammering in of essentials, and for revision so as to consolidate the position preparatory to a further advance. Examiners are not blameless, and some of the existing scurry and rush is caused by their unreasonable requirements. No one should be appointed to examine in any subject in which he himself, at some period, has not prepared candidates of a similar type for an examination of the like standing.

\section{France \\ [From our Correspondent in Paris]}

\section{Resident Hospital Appointments}

The front pages of the daily press have recently given considerable publicity to the competitive examination held last October for resident appointments in the Paris hospitals. To understand the events of the last few weeks, including the suicide of one of the persons concerned, it is necessary to show how all-important these hospital appointments are to every ambitious medical student. To have been an intern of a provincial hospital gives a certain cachet: to have been an intern of a Paris public hospital is to have climbed the first step of the latter to medical fame. Unless a student has held a resident appointment there is little chance of advancement, at any rate in Paris. It is this fact which makes these appointments so pre-eminently desirable. The identity of candidates used to be known to the examiners, but in order to promote impartiality a system of anonymous examination has been introduced. The unsigned, written answers to the questions are sealed up in an urn, which is not opened till the next stage of the examination. This consists in the reading of the papers to three examiners by " readers,". who are recruited from hospital residents and are paid for this work. Certain " readers" at the examination last October have been accused of detecting the identity of candidates, thanks to a prearranged code, and of correcting the papers as they read them to the examiners. The authorities state that 45 per cent. of the examination papers have been found marked, in contravention of the rules of anonymity. The examiners (recruited from the élite of the medical profession) have been subjected to much annoyance over the affair, and have naturally objected to the suggestion that three further examiners should deal with the original answers. Such a second examination could not possibly yield the same results as the first, however impartial all the examiners might be. It is therefore natural that examiners, present and potential, should have categorically refused to consent to such a course, and should even have threatened to appeal to the Conseil d'Etat should it be sanctioned. The authorities have decided to organize a fresh examination with new questions. Some idea of the magnitude of the problem can be gained from the statement that the vacant appointments numbered about eighty, for which there were over 600 candidates.

\section{A French General Medical Council}

French doctors have their syndicates-glorified trade unions-but there is no disciplinary corporation or order, such as the institution which governs the legal profession. The syndicates have done useful work, which they will doubtless continue to do, but they have been seriously hampered by lack of disciplinary powers. Without official support of the State, they have been more or less impotent in their dealings with " back-sliding" members. A member would freely invoke the aid of his syndicate when he needed it, but when he erred he could more or less ignore its injunctions. As long ago as 1845 an abortive attempt was made to establish a medical council with disciplinary powers. In those days the temptations to err were less attractive, less numerous, and more risky. Everyone knew what his neighbour did, a state of affairs singularly conducive to moral rectitude. For these and doubtless for other reasons the advocates of a disciplinary order had to accept defeat. On December 9th last year, however, the Chamber of Deputies adopted without discussion the draft of a new law for the creation of a medical order which will have jurisdiction over all members of the medical profession except those in the fighting Services. Every Department is to have its own order, but no doctor can belong to more than one, and its list of accredited members is to be brought up to date at the beginning of each year, and is to be published. Each order is to have a president, duly elected by its members, and a council 